\title{
Effects of FSHR polymorphisms on premature ovarian insufficiency in human beings: a meta-analysis
}

Wenling Huang ${ }^{1 *}$, Ying $\mathrm{CaO}^{2}$ and Lei Shi ${ }^{3}$

\begin{abstract}
Background: Whether follicle-stimulating hormone receptor (FSHR) polymorphisms are implicated in premature ovarian insufficiency (POI) remains controversial. Thus, we performed this study to explore correlation between FSHR polymorphisms and POI in human beings.

Methods: Literature retrieve was conducted in PubMed, Medline, Embase and CNKI. Odds ratios (ORs) and 95\% confidence intervals (Cls) were calculated.

Results: Sixteen studies were enrolled for analyses. No significant relationship with POI was found for rs6165 and rs6166 polymorphisms in overall analyses. Further subgroup analyses revealed that rs6166 polymorphism was significantly associated with the risk of POI in Asians with both FEM and REM. Nevertheless, we failed to detect any significant associations with POI for other ethnicities.
\end{abstract}

Conclusions: Our findings indicated that FSHR rs6166 polymorphism may serve as a potential genetic biomarker of $\mathrm{POI}$ in Asians, but not in other ethnicities.

Keywords: Premature ovarian insufficiency (POI), Follicle-stimulating hormone receptor (FSHR), Gene polymorphisms, Meta-analysis, Human beings, Asians

\section{Background}

Premature ovarian insufficiency (POI) is currently defined as apparent deterioration of ovarian function before the age of 40 in human beings [1]. It is characterized by an elevated level of follicle-stimulating hormone (FSH), a decreased level of estrogen, oligomenorrhea or amenorrhoea as well as an increased risk of osteoporosis and multiple cardiovascular diseases [2]. According to a recent epidemiological study, the prevalence of POI is estimated to be around $1 \%$ in women younger than 40 years old [3]. To date, the exact pathogenic mechanism of POI is still largely unknown. Nevertheless, there is mounting evidence to support that genetic factors play vital roles in its occurrence and development. First, family aggregation of POI in human beings is not uncommon, and it is estimated that about $10-30 \%$ of POI patients have positive

\footnotetext{
* Correspondence: wenlinghuang1968@163.com

${ }^{1}$ Reproductive Endocrinology Center, Dongfang Hospital, Beijing University of Chinese Medicine, No. 6 Fangxingyuan 1st Block, Fengtai District, Beijing, China

Full list of author information is available at the end of the article
}

family history [4]. Second, various genetic variants have already been found to be correlated with an increased risk of POI in human beings by previous experimental studies $[5,6]$. In summary, these findings jointly indicated that genetic predisposition to POI is crucial for its development.

FSH is a glycoprotein secreted by the pituitary gland, and it plays a crucial role in promoting follicle growth and regulating ovarian function by acting on the FSH receptor (FSHR) [7]. Therefore, it is biologically plausible that functional FSHR polymorphisms may result in dysfunction of FSH, lead to decreased ovarian function and give rise to the development of POI in human beings. The rs6165 and rs6166 polymorphisms are two commonly seen missense mutations of FSHR, the G to A transvertion at these two loci lead to amino acid residue substitution of the corresponding amino acid sequence, and thus these two polymorphisms may affect bonding of FSH and FSHR [8]. Previous studies have shown that rs6165 and rs6166 polymorphisms were actually correlated

(c) The Author(s). 2019 Open Access This article is distributed under the terms of the Creative Commons Attribution 4.0 International License (http://creativecommons.org/licenses/by/4.0/), which permits unrestricted use, distribution, and reproduction in any medium, provided you give appropriate credit to the original author(s) and the source, provide a link to the Creative Commons license, and indicate if changes were made. The Creative Commons Public Domain Dedication waiver (http://creativecommons.org/publicdomain/zero/1.0/) applies to the data made available in this article, unless otherwise stated. 
with a higher serum FSH level and reduced FSH efficiency in human beings $[9,10]$. Considering the functional significances of rs6165 and rs6166 polymorphisms, several pilot studies have already been conducted to investigate the possible correlation between these two polymorphisms and POI. However, the results of these studies were inconsistent and the sample size of individual studies was relatively small. Therefore, we conducted this meta-analysis to better analyze the roles of FSHR polymorphisms in POI.

\section{Methods}

\section{Literature search and inclusion criteria}

This meta-analysis was adhered to the Preferred Reporting Items for Systematic Reviews and Meta-analyses (PRISMA) guideline [11]. Potentially related literatures (published before September 2018) were retrieved from PubMed, Medline, Embase and China National Knowledge Infrastructure (CNKI) using the following searching strategy: (premature ovarian insufficiency OR premature ovarian failure OR POI OR POF) AND (polymorphism OR variant OR mutation OR genotype OR allele) AND (follicle stimulating hormone receptor OR FSHR). Furthermore, the references of retrieved articles were also screened for identification of other potentially relevant studies.

To test the research hypothesis of this meta-analysis, included studies must meet all the following criteria: a. casecontrol study on correlation between FSHR polymorphisms and POI in human beings; b. provide genotypic and/or allelic frequency of investigated FSHR polymorphisms; c. full text in English or Chinese available. Studies were excluded if one of the following criteria was fulfilled: a. not relevant to FSHR polymorphisms and POI in human beings; b. case reports or case series; c. abstracts, reviews, comments, letters and conference presentations. For duplicate publications, we only included the study with the largest sample size for analyses.

\section{Data extraction and quality assessment}

The following data were extracted from all included studies: (1) name of first author; (2) year of publication; (3) country and ethnicity of participants; (4) the number of cases and controls; and (5) the genotypic distribution of FSHR polymorphisms in cases and controls. Additionally, the probability value ( $P$ value) of Hardy-Weinberg equilibrium (HWE) test was also calculated.

The Newcastle-Ottawa scale (NOS) was employed to assess the quality of eligible studies from three aspects: (1) selection of cases and controls; (2) comparability between cases and controls; and (3) exposure in cases and controls [12]. The NOS has a score range of zero to nine, and studies with a score of more than seven were thought to be of high quality.
Two reviewers conducted data extraction and quality assessment independently. When necessary, the reviewers wrote to the corresponding authors for extra information or raw data. Any disagreement between two reviewers was solved by discussion until a consensus was reached.

\section{Statistical analysis}

All statistical analyses in the present study were conducted with Review Manager Version 5.3.3 (The Cochrane Collaboration, Software Update, Oxford, United Kingdom). ORs and 95\% CIs were used to assess the strength of correlation between FSHR polymorphisms and POI in all possible genetic models, and a $p$ value of 0.05 or less was considered to be statistically significant. Between-study heterogeneities were evaluated by $\mathrm{Q}$ test and $\mathrm{I}^{2}$ statistic. If $p$ value of $\mathrm{Q}$ test was less than 0.1 or $\mathrm{I}^{2}$ was greater than $50 \%$, between-study heterogeneities were considered to be obvious. Subgroup analyses by ethnicity of participants were subsequently conducted to obtain more specific results. Overall and subgroup analyses were performed with both fixed-effect models (FEMs) and random-effect models (REMs). Sensitivity analyses were carried out to test the stability of the results. Funnel plots were applied to evaluate possible publication bias.

\section{Results}

\section{Characteristics of included studies}

The literature search identified 63 potentially relevant articles. After exclusion of irrelevant and duplicate articles by reading titles and abstracts, 35 articles were retrieved for further evaluation. Another 19 articles were subsequently excluded after reading the full text. Finally, a total of 16 studies that met the inclusion criteria of our meta-analysis were included (see Fig. 1). Characteristics of included studies were summarized in Table 1.

\section{Overall and subgroup analyses}

To investigate potential correlations between FSHR polymorphisms and POI in human beings, 14 studies about rs6165 polymorphism (590 cases and 1170 controls) and 13 studies about rs6166 polymorphism (640 cases and 1333 controls) were enrolled for analyses. No significant relationship with POI was found for two investigated polymorphisms in overall analyses. Further subgroup analyses by ethnicity revealed that rs6166 polymorphism was significantly associated with the risk of POI in Asians with both FEM (additive model: $p=0.005$, OR $=$ 1.55, 95\% CI 1.14-2.09) and REM (additive model: $p=$ 0.005 , OR $=1.55,95 \%$ CI 1.14-2.09). Nevertheless, we failed to detect any significant associations with POI for other ethnicities (see Table 2). 


\section{Sensitivity analyses}

Sensitivity analyses were carried out to examine the stability of pooled results by eliminating studies that deviated from HWE. No changes of results were observed in any comparisons, which indicated that our findings were statistically reliable.

\section{Publication biases}

Potential publication biases in the current study were evaluated with funnel plots. No obvious asymmetry of funnel plots was observed in any comparisons, which suggested that our findings were unlikely to be influenced by severe publication bias.

\section{Discussion}

To the best of our knowledge, this is so far the most comprehensive meta-analysis on correlations between FSHR polymorphisms and POI. The overall and subgroup analyses revealed that the rs6166 polymorphism was significantly associated with the risk of POI in Asians under additive comparison. But we failed to detect any positive results for other ethnicities. The stability of the synthetic results was subsequently evaluated in sensitivity analyses, and no changes of results were observed in any comparisons, which indicated that our findings were quite stable and reliable.

There are several points that need to be addressed about this meta-analysis. Firstly, no obvious heterogeneities were

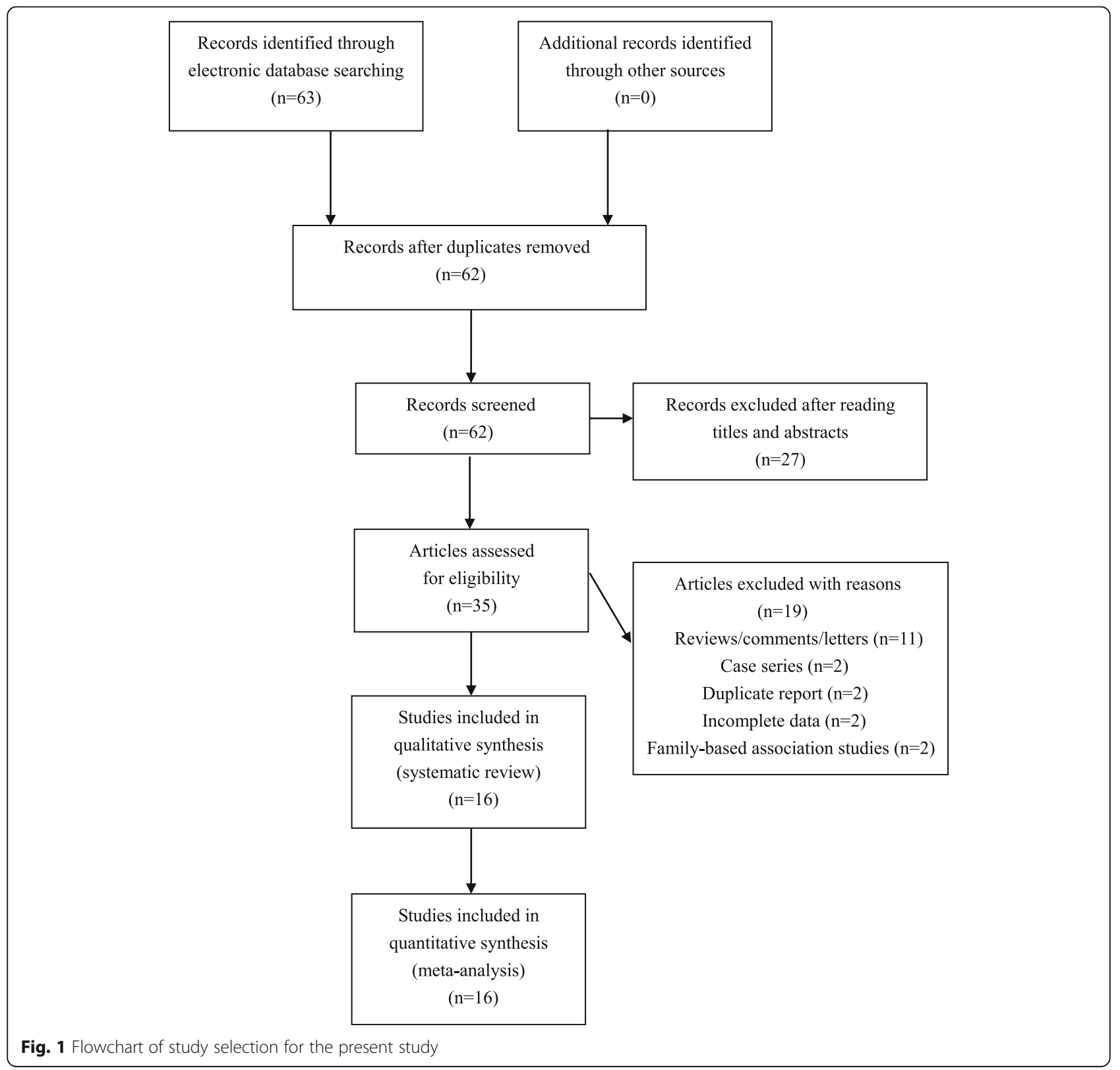


Table 1 The characteristics of included studies

\begin{tabular}{|c|c|c|c|c|c|c|c|c|}
\hline \multirow[t]{2}{*}{ First author, year } & \multirow[t]{2}{*}{ Country } & \multirow[t]{2}{*}{ Ethnicity } & \multirow{2}{*}{$\begin{array}{l}\text { Age (years) } \\
\text { Case/Control }\end{array}$} & \multirow{2}{*}{$\begin{array}{l}\text { Sample size } \\
\text { Case/Control }\end{array}$} & \multicolumn{2}{|c|}{ Genotype distribution } & \multirow{2}{*}{$\begin{array}{l}P \text {-value } \\
\text { for HWE }\end{array}$} & \multirow{2}{*}{$\begin{array}{l}\text { NOS } \\
\text { score }\end{array}$} \\
\hline & & & & & Cases & Controls & & \\
\hline \multicolumn{9}{|l|}{ rs6165 A/G } \\
\hline Bretherick 2008 & Canada & Mixed & $35.5 / 35.0$ & $55 / 105$ & NA & NA & NA & 7 \\
\hline Conway 1999 & UK & Caucasian & NA/NA & $49 / 51$ & NA & NA & NA & 7 \\
\hline Cordts 2015 & Brazil & Mixed & $31.0 / 31.0$ & $96 / 123$ & 29/48/19 & $55 / 53 / 15$ & 0.687 & 7 \\
\hline da Fonte Kohek 1998 & Brazil & Mixed & $22.2 / 31.0$ & $15 / 42$ & $3 / 8 / 4$ & $13 / 24 / 5$ & 0.228 & 7 \\
\hline Du 2010 & China & Asian & NA/NA & $40 / 92$ & 20/18/2 & $40 / 37 / 15$ & 0.207 & 7 \\
\hline Ghezelayagh 2018 & Iran & Mixed & NA/NA & $84 / 80$ & $24 / 50 / 10$ & $28 / 48 / 4$ & 0.004 & 8 \\
\hline Juárez-Rendón 2018 & Mexico & Mixed & $30.0 / 27.0$ & $20 / 50$ & $8 / 10 / 2$ & $26 / 17 / 7$ & 0.147 & 8 \\
\hline Liu 1998 & Germany & Caucasian & NA/NA & $5 / 4$ & $2 / 3 / 0$ & $3 / 1 / 0$ & 0.775 & 7 \\
\hline Ma 2015 & China & Asian & 29.8/29.3 & $63 / 58$ & $33 / 25 / 5$ & $28 / 25 / 5$ & 0.861 & 7 \\
\hline Sudo 2002 & Japan & Asian & $32.9 / 31.3$ & $17 / 163$ & NA & NA & NA & 7 \\
\hline Sundblad 2004 & Argentina & Caucasian & $27.0 / 27.2$ & $15 / 44$ & NA & NA & NA & 7 \\
\hline Tong 2001 & Singapore & Asian & $24.9 / 25.4$ & $16 / 236$ & 2/13/1 & $102 / 110 / 24$ & 0.475 & 8 \\
\hline Vilodre 2008 & Brazil & Mixed & NA/NA & $35 / 42$ & $9 / 19 / 7$ & $13 / 24 / 5$ & 0.228 & 7 \\
\hline Woad 2013 & New Zealand & Caucasian & NA/NA & $80 / 80$ & 28/34/18 & 25/38/17 & 0.718 & 7 \\
\hline \multicolumn{9}{|l|}{ rs6166 A/G } \\
\hline Bretherick 2008 & Canada & Mixed & $35.5 / 35.0$ & $55 / 105$ & NA & NA & NA & 7 \\
\hline Conway 1999 & UK & Caucasian & NA/NA & $49 / 51$ & NA & NA & NA & 7 \\
\hline Cordts 2015 & Brazil & Mixed & $31.0 / 31.0$ & $96 / 123$ & $30 / 52 / 14$ & $34 / 68 / 21$ & 0.190 & 7 \\
\hline da Fonte Kohek 1998 & Brazil & Mixed & $22.2 / 31.0$ & $15 / 42$ & $5 / 7 / 3$ & $13 / 24 / 5$ & 0.228 & 7 \\
\hline Du 2010 & China & Asian & NA/NA & $37 / 90$ & $16 / 19 / 2$ & $40 / 34 / 16$ & 0.077 & 7 \\
\hline Kim 2011 & South Korea & Asian & NA/NA & $83 / 176$ & 23/51/9 & $67 / 89 / 20$ & 0.238 & 7 \\
\hline Ma 2015 & China & Asian & $29.8 / 29.3$ & $63 / 58$ & $31 / 30 / 2$ & $32 / 22 / 4$ & 0.934 & 7 \\
\hline Sudo 2002 & Japan & Asian & $32.9 / 31.3$ & $17 / 168$ & NA & NA & NA & 7 \\
\hline Sundblad 2004 & Argentina & Caucasian & $27.0 / 27.2$ & $15 / 44$ & NA & NA & NA & 7 \\
\hline Tong 2001 & Singapore & Asian & $24.9 / 25.4$ & $16 / 236$ & $5 / 11 / 0$ & $91 / 132 / 13$ & $<0.001$ & 8 \\
\hline Vilodre 2008 & Brazil & Mixed & NA/NA & $35 / 42$ & $15 / 15 / 5$ & $13 / 24 / 5$ & 0.228 & 7 \\
\hline Woad 2013 & New Zealand & Caucasian & NA/NA & $80 / 80$ & 29/33/18 & 26/37/17 & 0.572 & 7 \\
\hline Yin 2016 & China & Asian & 31.3/29.2 & 79/118 & 25/37/17 & $43 / 45 / 30$ & 0.013 & 8 \\
\hline
\end{tabular}

Abbreviations: HWE Hardy-Weinberg equilibrium, NOS Newcastle-Ottawa scale, NA Not available

detected in overall analyses for two investigated polymorphisms, which indicated that eligible studies could be considered as homogeneous, and thus synthesize the results of these studies is statistically feasible. Secondly, the pathogenic mechanism of POI is highly complex, and hence it is unlikely that a single gene polymorphism can significantly contribute to its development. Therefore, to better illustrate potential correlations of certain gene polymorphisms with POI, we strongly recommend further studies to perform haplotype analyses and explore potential gene-gene interactions.

As with all meta-analysis, this study certainly has some limitations. First, our findings were based on unadjusted estimations due to lack of raw data, and failure to conduct further adjusted analyses for age, gender and co-morbidity conditions may impact the reliability of our findings $[13,14]$. Second, association between FSHR polymorphisms and POI may also be influenced by gene-gene and gene-environmental interactions. However, the majority of studies did not consider these potential interactions, which impeded us to perform relevant analyses accordingly [15]. Third, only retrospective case-control studies were included in this meta-analysis, and thus direct causal relation between FSHR polymorphisms and POI could not be established. Taken these limitations into consideration, the results of the current study should be interpreted with caution. 


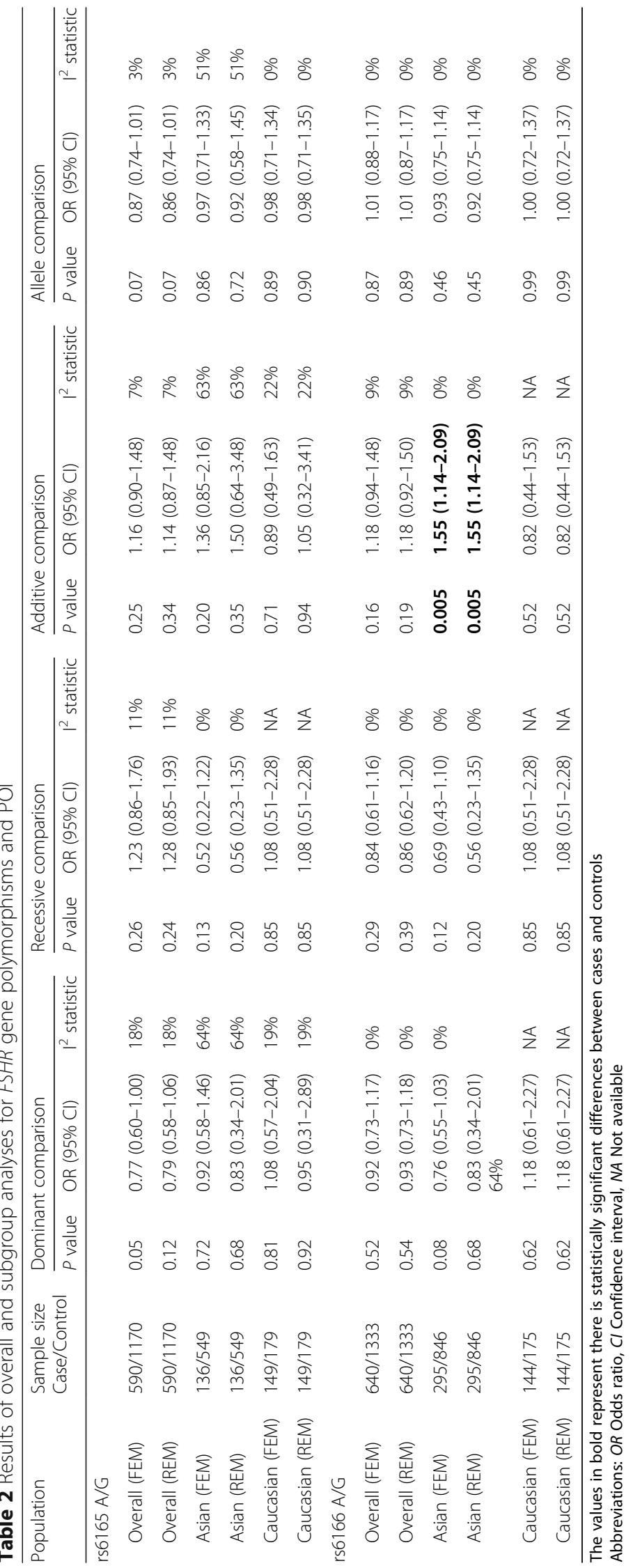




\section{Conclusion}

Overall, our meta-analysis suggests that the FSHR rs6166 polymorphism may serve as a potential genetic biomarker of POI in Asians, but not in other ethnicities. However, further well-designed studies with larger sample sizes are warranted to confirm our findings. Additionally, future investigations are needed to explore the potential roles of other FSHR polymorphisms in the development of POI.

\section{Abbreviations}

$\mathrm{Cl}$ : Confidence interval; FSHR: Follicle-stimulating hormone receptor; OR: Odds ratio; POI: Premature ovarian insufficiency

\section{Acknowledgments}

None.

\section{Ethical approval and consent to participate} Not applicable.

\section{Authors' contributions}

Wenling Huang conceived of the study, participated in its design. Wenling Huang and Ying Cao conducted the systematic literature review. Lei Shi performed data analyses. Wenling Huang drafted the manuscript. All authors have read and approved the final manuscript.

\section{Funding}

This study was funded by the National Natural Science Foundation of China (Grant no. 81704112).

\section{Availability of data and materials}

The current study was based on results of relevant published studies.

\section{Consent for publication}

Not applicable.

\section{Competing interests}

The authors declare that they have no competing interests.

\section{Author details}

${ }^{1}$ Reproductive Endocrinology Center, Dongfang Hospital, Beijing University of Chinese Medicine, No. 6 Fangxingyuan 1st Block, Fengtai District, Beijing, China. ${ }^{2}$ College of Traditional Chinese Medicine, North China University of Science and Technology, Hebei, China. ${ }^{3}$ Research Office, Dongfang Hospital, Beijing University of Chinese Medicine, Beijing, China.

Published online: 19 October 2019

\section{References}

1. Jankowska K. Premature ovarian failure. Prz Menopauzalny. 2017;16:51-6.

2. Laven JS. Primary ovarian insufficiency. Semin Reprod Med. 2016;34:230-4.

3. Yonkers KA, Simoni MK. Premenstrual disorders. Am J Obstet Gynecol. 2018; 218:68-74.

4. Ferrarini E, Russo L, Fruzzetti F, et al. Clinical characteristics and genetic analysis in women with premature ovarian insufficiency. Maturitas. 2013;74: 61-7.

5. Rossetti R, Ferrari I, Bonomi M, et al. Genetics of primary ovarian insufficiency. Clin Genet. 2017;9:183-98.

6. Jiao X, Ke H, Qin Y, et al. Molecular genetics of premature ovarian insufficiency. Trends Endocrinol Metab. 2018;29(11):795. https://doi.org/10. 1016/j.tem.2018.07.002

7. Meduri G, Bachelot A, Cocca MP, et al. Molecular pathology of the FSH receptor: new insights into FSH physiology. Mol Cell Endocrinol. 2008;282: 130-42.

8. Trevisan CM, Peluso C, Cordts EB, et al. Ala307Thr and Asn680Ser polymorphisms of FSHR gene in human reproduction outcomes. Cell Physiol Biochem. 2014;34:1527-35.

9. Borgbo $T$, Jeppesen $\mathrm{JV}$, Lindgren I, et al. Effect of the FSH receptor single nucleotide polymorphisms (FSHR 307/680) on the follicular fluid hormone profile and the granulosa cell gene expression in human small antral follicles. Mol Hum Reprod. 2015;21:255-61.

10. La Marca A, Papaleo E, Alviggi C, et al. The combination of genetic variants of the FSHB and FSHR genes affects serum FSH in women of reproductive age. Hum Reprod. 2013;28:1369-74.

11. Moher D, Liberati A, Tetzlaff J, et al. Preferred reporting items for systematic reviews and meta-analyses: the PRISMA statement. Ann Intern Med. 2009; 151:264-9.

12. Stang A. Critical evaluation of the Newcastle-Ottawa scale for the assessment of the quality of nonrandomized studies in meta-analyses. Eur J Epidemiol. 2010;25:603-5.

13. Xie $X$, Shi $X$, Liu M. The roles of TLR gene polymorphisms in atherosclerosis: a systematic review and meta-analysis of 35,317 subjects. Scand J Immunol. 2017:86:50-8

14. Shi $X$, Xie $X$, Jia $Y$, et al. Associations of insulin receptor and insulin receptor substrates genetic polymorphisms with polycystic ovary syndrome: a systematic review and meta-analysis. J Obstet Gynaecol Res. 2016;42:844-54.

15. Xie $X$, Shi $X, X u n$, et al. Endothelial nitric oxide synthase gene single nucleotide polymorphisms and the risk of hypertension: a meta-analysis involving 63,258 subjects. Clin Exp Hypertens. 2017;39:175-82.

\section{Publisher's Note}

Springer Nature remains neutral with regard to jurisdictional claims in published maps and institutional affiliations.
Ready to submit your research? Choose BMC and benefit from:

- fast, convenient online submission

- thorough peer review by experienced researchers in your field

- rapid publication on acceptance

- support for research data, including large and complex data types

- gold Open Access which fosters wider collaboration and increased citations

- maximum visibility for your research: over $100 \mathrm{M}$ website views per year

At BMC, research is always in progress.

Learn more biomedcentral.com/submissions 